\title{
The Evolution of Seismicity and Subsequent Learning Experiences in Deep Lead, Mount Isa Mines, Xstrata Zinc
}

\author{
I.G.T. Thin, N.S. Edkins, L.J. Jeschke, A.P. Winchester Mount Isa Mines, Xstrata Zinc, Australia
}

When compared to seismically active underground mines, the Mount Isa Mines Deep Lead can be considered to be seismically 'quiet'. Historically, rock noise has been experienced in adverse conditions associated with diminishing crown pillars (rather than a day-to-day occurrence). However, some of the Deep Lead orebodies exhibit intermittent microseismicity, the levels of which are significant in terms of Mount Isa Mines standards.

Current mining activities in Deep Lead are at a depth of just over $1 \mathrm{~km}$ below surface, and represent high-grade zinc, lead and silver sources for the Lead Mine. This paper presents a case study of events leading up to the installation of a remote seismic system and subsequent mining of the 14 group of orebodies covering the issues encountered during development over time; the philosophy behind the initial stope designs; the performance of early stope extractions; current issues in Deep Lead; and the experiences learnt from Deep Lead.

\section{INTRODUCTION}

The Mount Isa Mines Lead Mine has been operational for over 80 years and has had some 130 million tonnes extracted from it through various mining methods. With the completion of the K68 surface decline in early 1999, three definitive mining areas were created; namely the upper, middle and lower. While all three mining fronts have experienced varying levels of microseismic activity over time, the lower mining front (or Deep Lead) has experienced a greater level of activity than the other two mining areas.

Mining activities in the Lead Mine vary in depth from $200 \mathrm{~m}$ to $1200 \mathrm{~m}$ below the surface. The Deep Lead region itself lies at a depth of $920 \mathrm{~m}$ (19A Sublevel) to 1,035 m (21D Sublevel), refer to Figure 1. Current extraction rates are 800,000 tonnes per year, of which 320,000 tonnes are coming from Deep Lead. Typical stope sizes in Deep Lead equate to approximately 30,000 tonnes (with average grades of $6.2 \%$ $\mathrm{Pb}, 5.0 \% \mathrm{Zn}$ and $150 \mathrm{~g} / \mathrm{t} \mathrm{Ag})$.

\subsection{Geology}

The producing source of Deep Lead has to date been the 14 group of orebodies. The group consists of the 14, 14/10 and 14/30 orebodies. This sequence is made up of shales and pyritic shales, as well as massive pyrite units and some silica dolomite (in parts), which dip at $65^{\circ}$ to $35^{\circ}$ to the west (note that the classic Racecourse orebodies tend to dip at $70^{\circ}$ to $65^{\circ}$ to the west). The dip of the Deep Lead orebodies flattens noticeably with depth.

\subsection{General Mining}

The 14 Orebody extraction sequence retreats in two sections (north and south directions) towards a central transverse pillar, which forms the main access to several hangingwall orebodies yet to be mined. Elevated levels of induced rockmass damage to those experienced in the middle and upper levels of the Lead Mine were anticipated (Cai, 1996, Tyler, 1996). As such, a more intense ground control system was required and implemented during development, particularly in the southern extent of 14 Orebody. Development and production from the northern end has experienced comparatively less microseismicity and subsequent rockmass damage than the southern end.

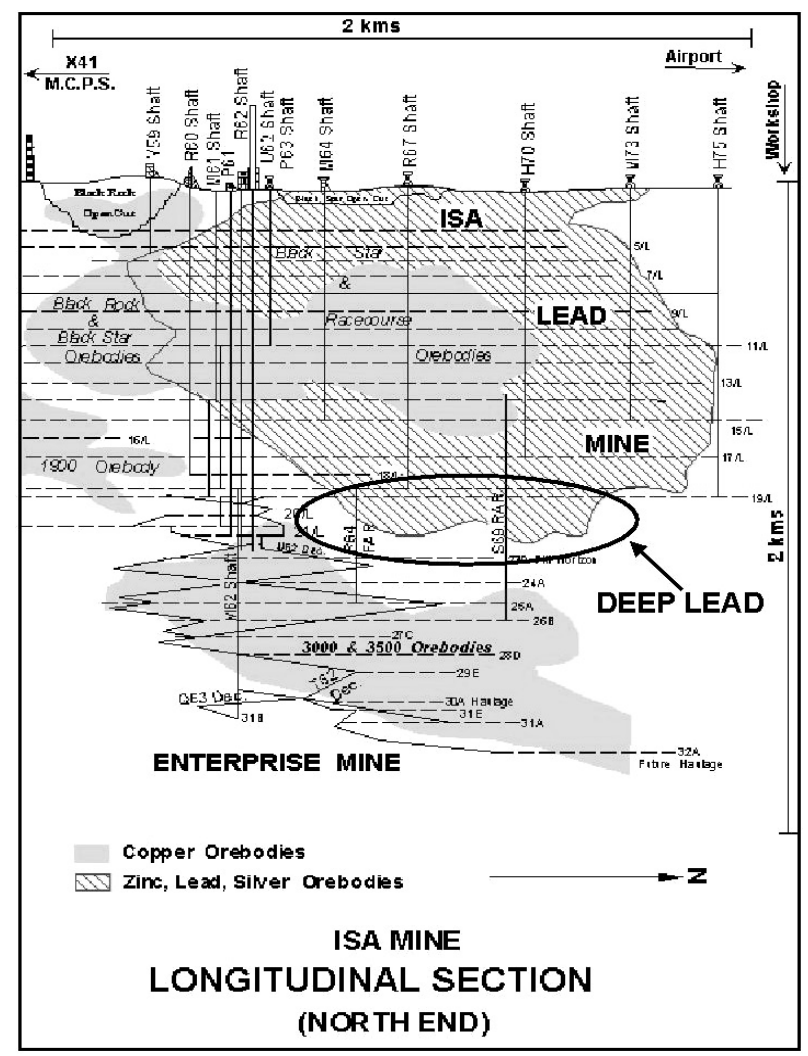

FIG. 1 Longitudinal section looking west showing the location of Deep Lead in relation to the Lead Mine and Enterprise Mine

Seismicity was historically monitored by simple qualitative means in the Lead Mine, an approach that was extended down to Deep Lead. This approach continued until the rock noise increased to a level that warranted a more sophisticated approach, with a remote ISS seismic system subsequently installed. Microseismic activity is now monitored via this system on a continual basis. 
While microseismic activity in Deep Lead has increased with progressing extraction (and at times to significant levels), it remains intermittent. To date, the activity is an indicator of elevated stress, with no rock bursting experienced. Rockmass damage has been confined to sill drive development and is within the capacity of the installed ground control (which has so far not included any form of specific seismic support elements).

\section{HISTORICAL SEISMICITY IN THE LEAD MINE}

The Lead Mine has experienced varying degrees of microseismicity throughout its operational life. The majority of the activity, and occasional associated rockmass damage, has been related to post production firings (see Figure 2). With such cases, the activity has generally decreased to a level that was considered acceptable to allow normal mining tasks to resume (this period of time was usually when the firing boards had re-opened after the end-of-shift firing). However, there have been occasions when the level of microseismicity has been of a significant level that it has had an impact on the operation (these incidents have been infrequent rather than day-to-day occurrences). Several such examples are briefly discussed.

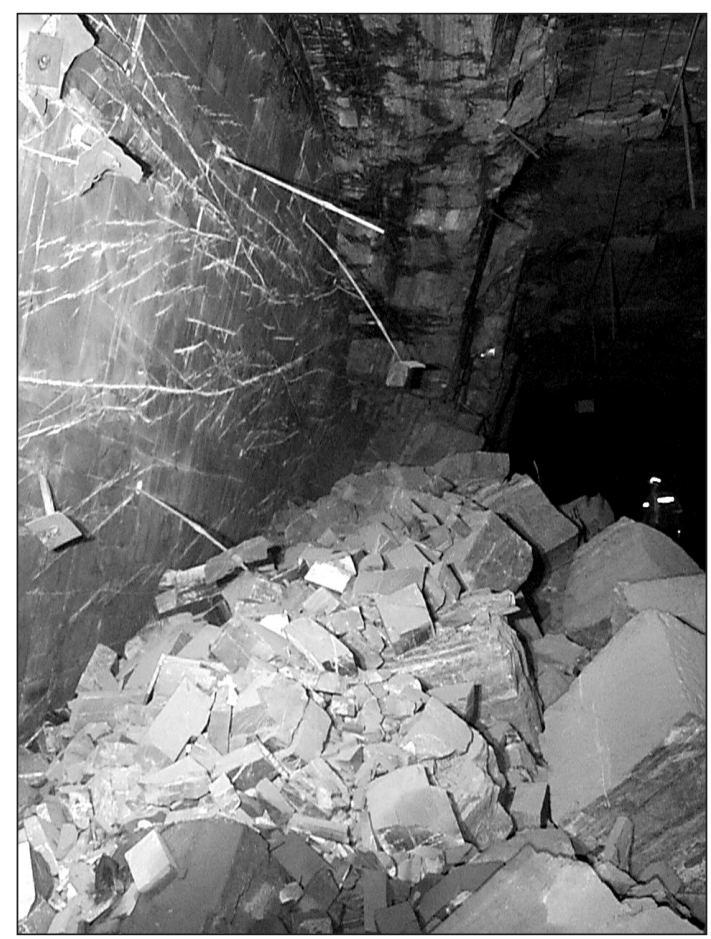

FIG. 2 An example of rockmass deterioration (in the hangingwall of sill drive) induced due to stress changes, a small-sized pillar and production firings from an adjacent bench (photograph looking north). Despite the level of damage, the associated rock noise was found to dissipate relatively quickly

\subsection{Level Crown Pillar Failure}

One of the methods in which the classic Lead Mine Racecourse orebodies were extracted was by the mechanised cut and fill method (or MICAF), by an advancing up-dip mining front incorporating the 'flat-backing' (or breast stoping) approach.

An advantage of the MICAF method was the higher ore recovery achieved and the need to only leave a minimum thickness of horizontal crown pillar. However, with such a method, the stability of the crown pillars was a major concern (as the thickness of the crown pillar decreased the stresses within it increased, especially in the immediate back of the advancing stope and around the development openings in the crown pillars).

Stopes were kept in line perpendicular to bedding so as to ensure that the major principal stress would always act normal to bedding, in order to eliminate the possibility of crown instability being induced by slip on the bedding planes (MacLeod-Carey, 1969).

In 1969, MacLeod-Carey reports on one such crown pillar (the 11 Level crown above 7 and 8 orebodies), were very high stresses developed in the pillar to the point that spalling of intact rock, rockfalls, significant rock noise and rock bursts occurred. The magnitude of some of these bursts was such that the induced vibration was felt on surface (Lee, 1980). As a result of these induced conditions in the crowns, the extraction sequence was changed.

\subsection{Level Cave}

Early in 1999, it was noted that several regions in the upper mining area of the Lead Mine were deteriorating. Mining activities in this area had been dormant for many years and had only become active after the completion of the K 68 surface decline, which broke through into existing development on 4 Level. The deteriorating ground conditions were particularly noticeable with large and continuous extensional cracks opening up (see Figure 3) in parts of the old development associated with the crowns of unfilled stopes in the upper mining front (Sharrock et al., 2002).

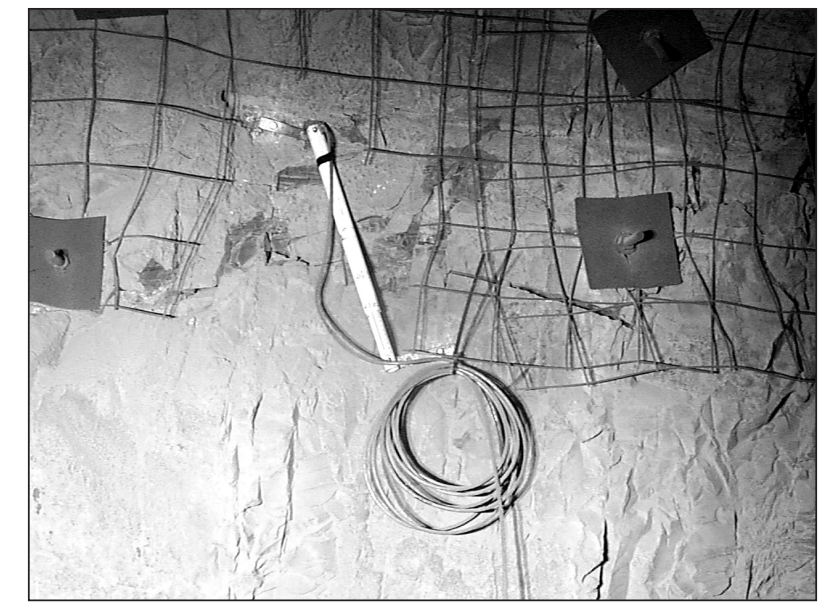

FIG. 3 Photograph showing one of several crack extensometers monitoring the intact rockmass failure in the sidewall of a north-south striking drive on 6 Level. The drive is adjacent to a series of unfilled stopes (the ground was slowly moving towards the voids and subsequently 'tearing' the rockmass apart in tension

However, in late 1999, a Development Crew working on 5 Level reported activity from within an old stope located near to the K68 decline. Investigations surrounding the activity (which consisted of continuous audible rock noise and fall-off) found that the crown of stope K682 was failing. The caving region was seen to exist within a large hanging pendent pillar.

It was thought that rib pillars between three old stopes (K679, K682 and K685) had failed prior to the initiation of the cave, creating a combined strike crown surface in the order of $125 \mathrm{~m}$ (Sharrock et al., 2002). Probe holes discovered that the cave was progressing vertically up towards the newly developed surface decline. Monitoring equipment was installed into the crown of the cave to detect further caving in the area until tight filling of the void with aggregate backfill arrested the cave. Up until this point, continuous and at 
times significant microseismicity was heard and felt (ranging from popping and cracking to thumps), over a time period of several weeks.

\subsection{Level Cave}

In late 2000, an entirely separate cave developed from 7 Level, discovered during probe drilling on 6 Level that intersected a stope void. Soon after the probe-holes had been drilled, the cave was seen to accelerate both in terms of rate of advance and areal extent (Sharrock et al., 2002). Further probe drilling discovered that two large sub-level open stopes (J692 and J697, which had not been tightly backfilled) had joined together as a result of the rib pillar between them failing and were caving vertically up and along the strike of the orebody. The combined size of the 'newly' exposed crown surface was approximately $95 \mathrm{~m}$ along strike and $60 \mathrm{~m}$ wide.

In terms of microseismicity, the intensity was found to increase with time. Initially rock noise was being described as constant cracking and popping/ticking, increasing to deep seated cracks and thumps at its peak (rock noise was clearly audible on 6 Level during the early stages - the seismogenic zone ahead of the actual cave front on 7 Level). It was also noted that the rock noise during the initial stages was continuous over several days, to intermittent during the significant peak levels. In addition, the significant level of rock noise was predominantly heard and felt on 6 Level in the southern end of the cave.

The filling of the cave void was a long and complicated process that took several months to complete. The process involved firing two long hole winzes (LHW) into the cave crown from 6 Level. There were concerns raised with such proposed firings in such a sensitive area in that the firings could re-activate the cave. The LHW's were eventually located on the edges of the cave crown rather than in the cave arch (the edges were considered to be less sensitive than the arch). Because of the concerns, an accelerometer was installed on the northern end of the cave boundary on 7 Level (location limited due to access constraints), which allowed for remote qualitative monitoring of the microseismic activity in the area (see Figure 4).

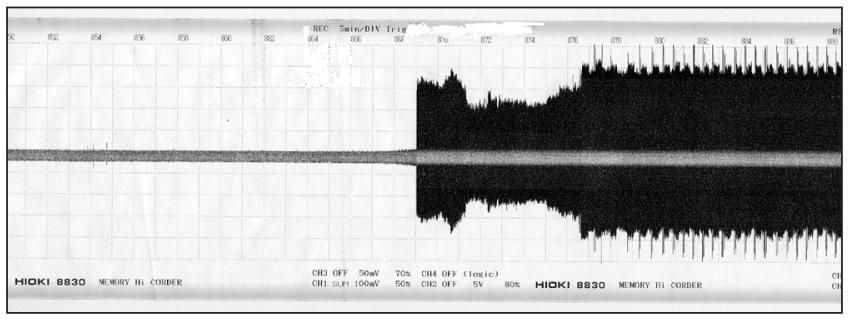

FIG. 4 A section of chart recorded by the accelerometer. The chart shows a distinct change in microseismic activity, which corresponded to the start of reports of rock noise being heard underground (the activity started just before $4.00 \mathrm{pm}$, and continued for several hours)

The 7 Level cave and associated microseismicity continued for several days, with aggregate being tipped into the cave void in an attempt to slow the cave growth down. After only a few days, the progressive failure had consumed approximately $60 \mathrm{~m}$ of rockmass before the cave arrested (but without choking itself off). The arresting behaviour was believed to have possibly occurred due to a reduced crown surface with the formation of a stable arch. The consequences of this particular incident where considered significant in that an ore source and access way were lost.

\subsection{Stope H742 and 7350 x/c Failure}

A final example of significant microseismic activity occurred when one of the last 5 Orebody stopes was extracted (stope H742, which was designed with a HW and FW lens, from 15B Sublevel to 13 Level). The section of stope in question (H742 FW) was adjacent $20 \mathrm{~m}$ north of the $7350 \mathrm{x} / \mathrm{c}$ transverse pillar. The $7350 \mathrm{x} / \mathrm{c}$ pillar was used for access purposes on several levels. Stope H742 HW lens was extracted prior to H742 FW without any issues and only limited rock noise. To the south of the pillar was a main orepass (I73, from 11 Level to 19 Level). During the initial stages of the stope extraction, rock noise was felt and heard throughout the surrounding area. The level of noise progressively increased from continuous cracking to deepseated thumps. The length of time taken for the activity to settle down also progressively increased, to the point that restrictions were placed on all access routes to the stope for several days following each production firing. Regular falloff from within the stope was also heard during this time.

As the microseismicity continued, so did the level of rockmass deterioration. The deterioration was gradual on the various levels of the transverse pillar, as well as in the remaining stope development. Within the transverse pillar, ground deterioration progressed from scats, to onion peeling of the sidewalls, to the eventual collapse of the drive back in the area immediately adjacent to the stope (see Figure 5). During this time, the orepass to the south of the pillar had been 'self-mining' in a northerly direction (reflecting the high horizontal stress direction striking parallel to the pillar axis in an east-west direction), to the point where it breached the pillar (a distance of $15 \mathrm{~m}$ from its original location).

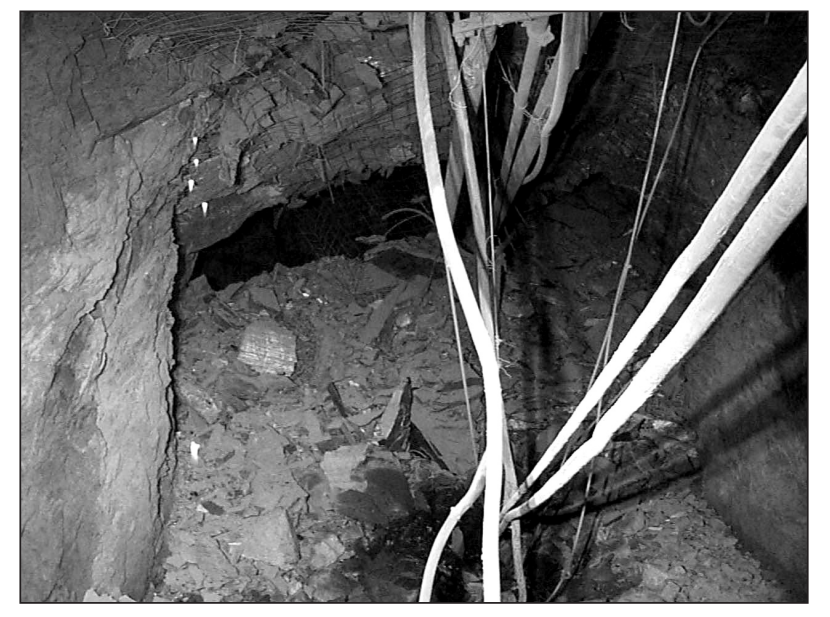

FIG. 5 Photograph looking west, showing the eventual failure of the back of the $7350 \mathrm{x} / \mathrm{c}$ on 15B Sublevel at the point adjacent to stope $\mathrm{H} 742$, conditions compounded with 173 orepass breaching the cross-cut

The rockmass deterioration and rock noise continued for a couple of weeks, with an eventual failure of the 13 Level crown between the stope and MICAF above. The I73 OP collapsed and the access through the pillar was lost on several levels as a result of the deterioration, the consequence of which was to considerably increase the overall travel time to parts of the mine (particularly in the middle mining front).

\section{INITIAL PREDICTIONS AND CONCERNS OF MICROSEISMICITY IN DEEP LEAD}

Deep Lead was new territory for the Lead Mine. As part of the feasibility study, the effects of stress were modelled and a suitable sequence designed to minimise stress impacts (Cai, 1996). At the time of the feasibility study it was also recognised that a seismic system may be necessary. 
The biggest concern was the lack of knowledge regarding the stress field surrounding the Deep Lead region of the Lead Mine. Above 19L, the stress was primarily across the strike of the orebody (east-west), while deeper around 21C in the Enterprise Mine, the primary stress was along the strike of the orebody (north-south). This meant the Deep Lead region was potentially situated in a transition area, where the stress changed orientation.

As previously discussed (refer to Section 2.1), the 14Orebody group has in the past displayed rock burst conditions in the middle and upper levels of the Lead Mine (Lee, 1980). The concern was the potential rock burst conditions eventuating in Deep Lead.

The O68 fault severs and displaces orebodies from 12L to 21D in the Lead Mine. There has not been any significant movement or slip along the fault in the middle and upper levels. However, there was concern that this would not be the case for the fault in Deep Lead due to the increase in stress (and more importantly the stress directions).

The ground conditions, stope geometries and regional stability to the north of $6755 \mathrm{x} / \mathrm{c}$ were all expected to be significantly more feasible and economic than those south of $6755 \mathrm{x} / \mathrm{c}$. The north extent was considered to have some shielding from stress due to the extraction of the over-lying $14,14 / 10,14 / 30,13 / 80,13,12,11 / 60$ and 7 orebodies. These filled voids provided a $200 \mathrm{~m}$ foot print of ground with lower stress conditions. The south extent had limited shielding and was located on the southern abutment of the Lead Mine. As such, the southern region had both the primary transverse stress and the southern abutment stress to contend with.

\section{DEVELOPMENT OF DEEP LEAD}

In 1996, the Lead Mine was scheduled to complete all production by 1999. The original Deep Lead extraction therefore was set up to extract as much of the 14, 14/10, $14 / 30$ orebodies within the 3 year time frame. The primary development began in late 1996, with the turning out of the P69 decline from 19B Sublevel.

The general design based around the 3 year extraction principle was to set up a longitudinal series of panel stopes between 19L/19A and 20B/20C that retreated back to a central cross cut-pillar (centred around $6755 \mathrm{mN}$, see Figures 6 and 7). The thought was that over a 3-year time frame, only the top $35 \mathrm{~m}$ portion of the Deep Lead orebodies could be feasibly extracted. The retreat of the 14 group of orebodies to a central infrastructure cross-cut was always known to be a poor way to manage the stress, but the rapid extraction expected was supposed to minimise the duration of the effect of stress redistribution.

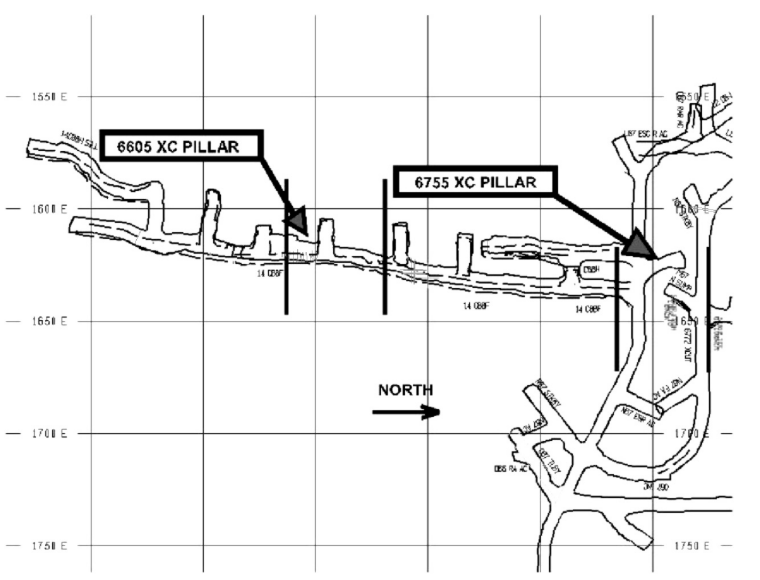

FIG. 6 Plan of 20B/20C Sublevel, showing the bottom sub of the southern end of Deep Lead

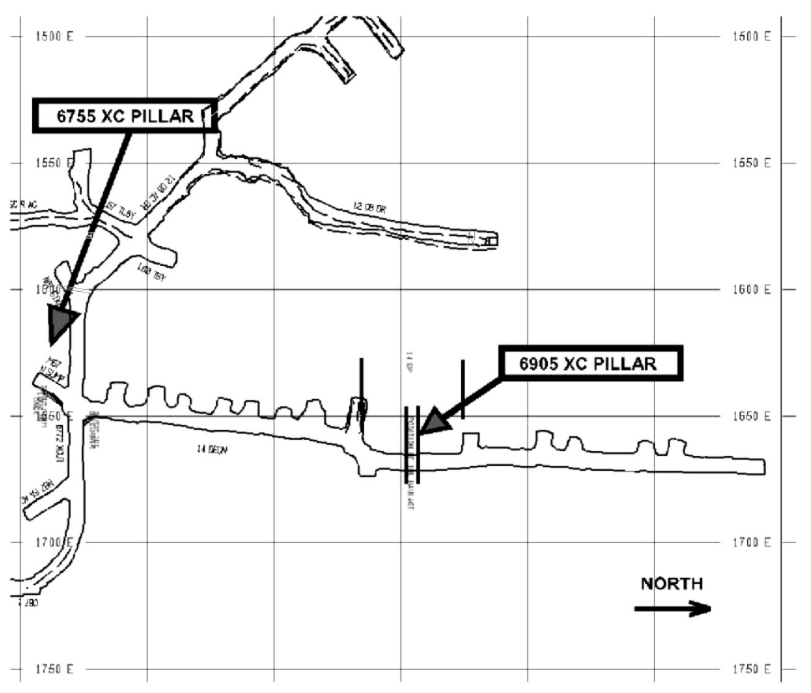

FIG. 7 Plan of 20D/20E Sublevel, showing the bottom sub of the northern end of Deep Lead

Three regional pillars were incorporated in the designs, all surrounding the existing 19L-rail haulage cross-cuts. The cross-cuts had $40 \mathrm{~m}$ strike lengths and centred on $6605 \mathrm{mN}$, $6755 \mathrm{mN}$ and $6905 \mathrm{mN}$. This allowed between 2 and 3 stope voids to be separated by rib pillars between each regional pillar.

The Deep Lead extraction involved the $11 \mathrm{~m}$ true width $\mathrm{D}$ and E blocks (see Figure 8) north of the $6755 \mathrm{x} / \mathrm{c}$ pillar, which were to be excavated $10 \mathrm{~m}$ higher in RL than the southern $30 \mathrm{~m}$ true width $\mathrm{C}$ and $\mathrm{B}$ blocks. The primary reason was due to the 19L rail haulage of $6905 \mathrm{x} / \mathrm{c}$ still considered as a high traffic cross-cut. The northern Deep Lead development needed to straddle above and beneath this cross-cut. The other reason was to assist in maintaining a rockmass at the $6755 \mathrm{x} / \mathrm{c}$ by reducing the number of ballrooms in the centre of the two sets of retreating void fronts.

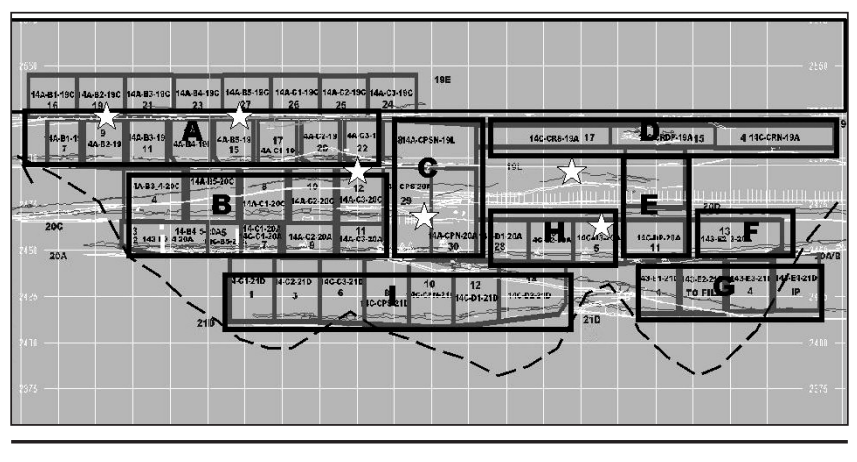

FIG. 8 Longitudinal section of Deep Lead (looking west) with the region divided into the various mining blocks. Also included are the locations of the geophones for the seismic system shown by the white stars (refer to Section 8.2) - the dashed line indicates the extent of Deep Lead

The 19/19A Sublevel northern development was driven along the distinct and planar hangingwall ore contact, with few problems and no rock noise. Fully encapsulated resin bolts and twin strand garford cables were installed along strike and in the hangingwall and back of the drive, to counter the expected changes in stress during the retreating extraction sequence. The slot regions were footwall recesses just deep enough to accommodate the production drill rig (see Figure 9). All cut-off recesses were pre-developed, and again the ground conditions were competent and without microseismic activity being induced. 


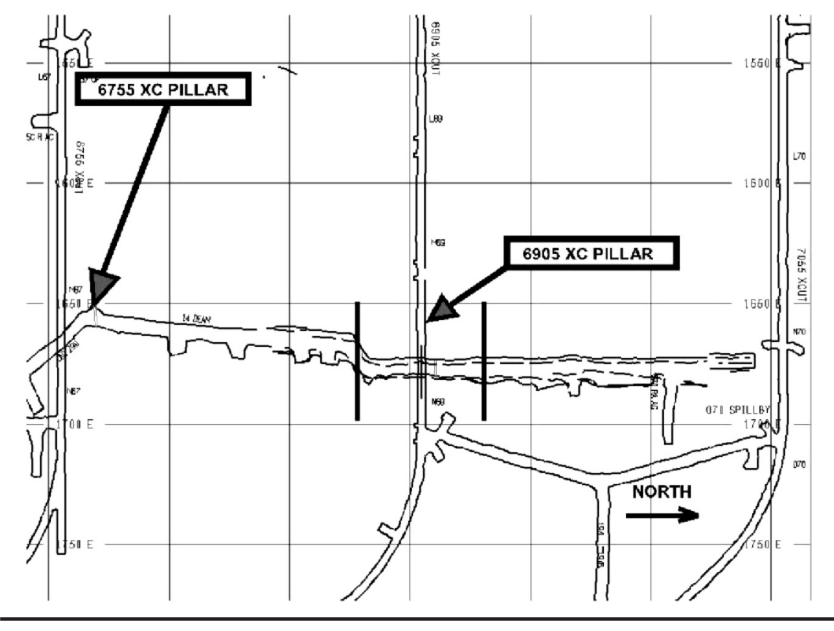

FIG. 9 Plan of 19/19A Sublevel, showing the top sub of the northern end of Deep Lead

The 19L southern development began displaying contrasting characteristics to the rockmass in the northern end. Once the development along strike began, the hangingwall was non-planar and the ground was talking after each cut. The original twin drives (FW and HW) that were developed to accommodate the $30 \mathrm{~m}$ true orebody width were stopped on both the top and bottom levels (19L/19A and 20B/20C respectively) due to the severe induced rock noise and degradation being experienced in the HW drive on 20B/20C (refer to Figure 6). The pre-development on 19L/19A continued in the HW drive only.

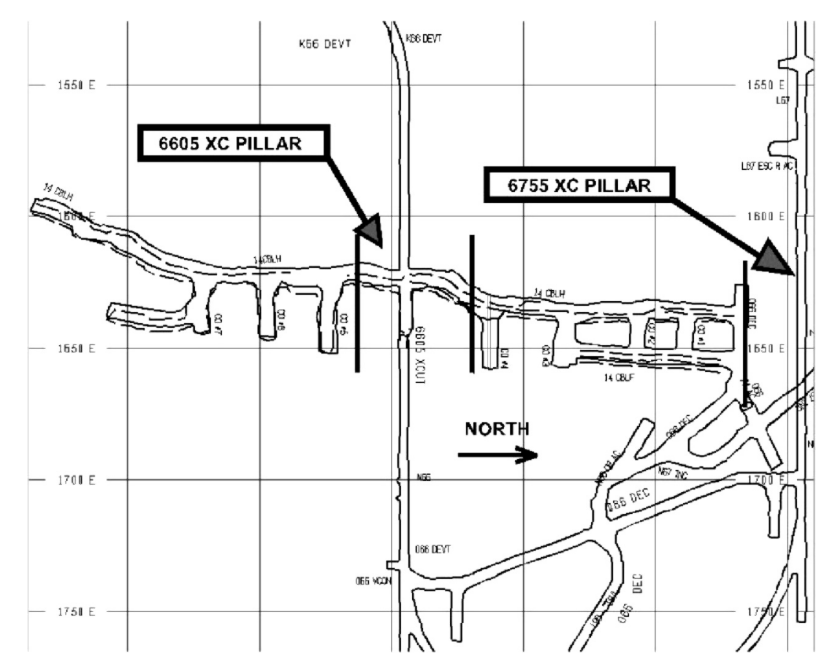

FIG. 10 Plan of 19/19A Sublevel, showing the top sub of the southern end of Deep Lead

The 20D/20E Sublevel northern development was driven along the foot wall to allow the production firings to rill down the footwall plane and thus minimise the rill against the firing face where the loader could not get around the corner to extricate the broken ore. The cut off recesses were mined into the HW plane to locate the ore boundary (refer to Figure 7). The slight undercutting of the northern orebody hangingwall had no detrimental effects during production. All cut off recesses were again pre-developed.

The 20B/20C southern development was driven initially along both the footwall and hangingwall boundaries. As soon as the turn out of the sill drives began the stress distributions became apparent. Onion peeling of the backs began three cuts behind the advancing face, with the footwall and hangingwall buckling into the drive. The associated rock noise was, at times, considered significant, with deep-seated thumps felt and heard over the operating development Jumbo. At about $6720 \mathrm{mN}$ and then further south, the damage due to stress changes had been consistently affecting the drive. Due to the consistency of the deterioration processes, the southern drives needed to rest for 12 hours after the firing of the development face. This course of action was deemed necessary due to the excessive noise and slabs peeling off the back.

The advancing rate was reduced to the point that for a while, only one cut per week was being taken. Installed ground control was increased during this time. The back, hangingwall and footwall were mechanically scaled, after which split sets and mesh was initially installed. Once the meshing was complete, fully encapsulated resin bolts were installed in the back to provide the increased strength when the stress relaxation occurred as the face advanced for the next $2-3$ cuts.

During the period when ground conditions and rock noise were particularly bad, cable bolts were also installed in the back and hangingwall before each cut advanced (this was instead of a campaign process of cable bolting several cuts at once). It was felt that without this level and process of reinforcement applied to the development cycle, the ground would have buckled and encroached into the drive.

It was soon apparent that there was a need to bolt the footwall, as slabs of rock would slide down the footwall without warning and placed operators at risk. The decision to bolt and mesh the footwall, was an increase to the standard ground control pattern which only had the back and hangingwall bolted in sill drive development.

\section{STRESS IN THE DEEP LEAD MINING REGION}

With the onset of stress related rockmass deterioration and the associated microseismic activity, questions were raised about the stability and sequencing of the stopes and their influence on the access drives and regional pillars in the area. Of particular concern was maintaining the access to the hangingwall side of 14 orebodies, where additional reserves are located. The stability of the $6755 \mathrm{x} / \mathrm{c}$ had to be maintained in order to access the proposed 7,8 and 12 orebody retreats (Beck, 2004a).

A subsequent investigation of the stress redistribution issues identified a change in the pre-mining stress field as one likely critical parameter. A program of stress measurements was commenced late in 2000 to determine the pre-mining stress measurements in the Deep Lead region (Sharrock and Duplancic, 2001).

These measurements proved very difficult to conduct (with measurements taken on 20D level). The final results of a lengthy measurement campaign showed that high magnitudes of stress existed in orientations very different to the traditional Lead Mine stress field (Sharrock and Duplancic, 2001, Slade 2002).

In the past, a large number of stress measurements have been conducted in the Lead Mine. From these tests, an analysis of the results showed a clear relationship between depth and the principal stresses. Figure 11 shows that the major principal stress increases uniformly with depth until a value of around $40 \mathrm{MPa}$ is achieved. At this value the relation between depth and major principal stress is then not well defined. It is postulated that at around $800 \mathrm{~m}$ to $1000 \mathrm{~m}$ below surface, an additional factor is introduced to change the relation between major principal stress and depth. 


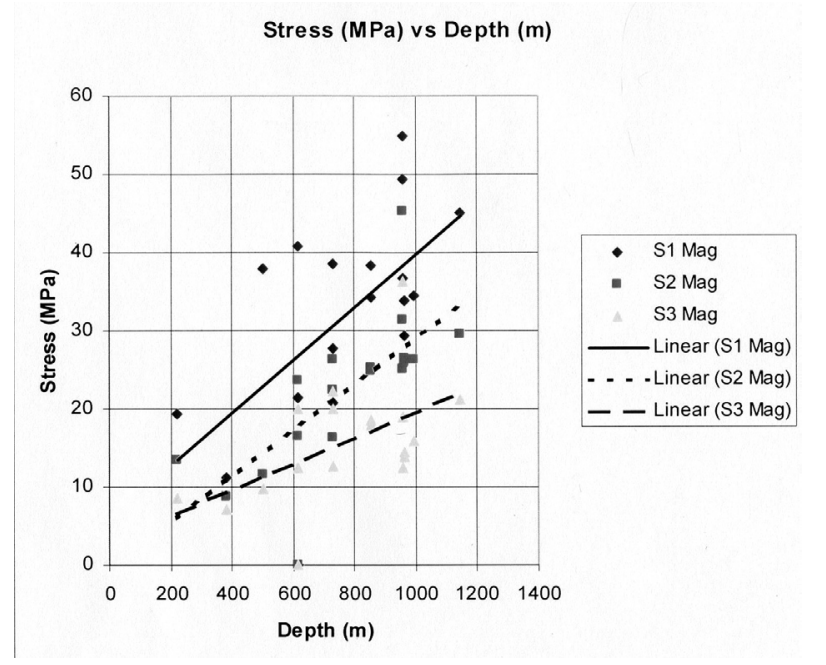

FIG. 11 Graph showing the relationship between pre-mining stress and depth in the Lead Mine (after Sharrock and Duplancic, 2001)

Stress measurements in Deep Lead Mine support the idea that the pre-mining stress distribution is related to the Enterprise Mine pre-mining stress field rather than the traditional Lead Mine pre-mining stress field.

In the past, the pre-mining stress measurements in the Lead Mine have strongly indicated that the major principal stress is oriented perpendicular to the bedding planes, in an east-west direction. In comparison, the pre-mining stress field in Enterprise Mine is shown through some measurements to have a major principal stress oriented in a north-south direction at a dip of around 4 degrees. It has been concluded that a stress gradient (in addition to the vertical stress gradient) must exist between the Lead Mine orebodies above 19L, and the Enterprise orebody. Examination of the geometry suggests that the Deep Lead region between 19L and 23L would represent the transition zone (see Figure 12).

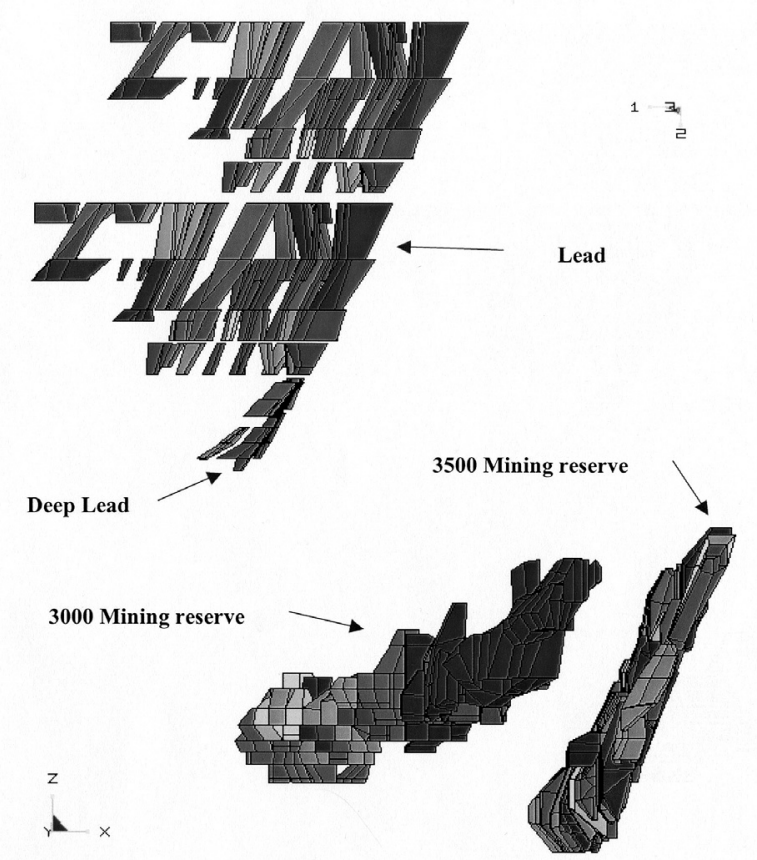

FIG. 12 Schematic representation looking north of the Lead Mine, Deep Lead and Enterprise Mine (after Sharrock and Duplancic, 2001)
Following the stress analysis, interpretation and observations underground, it was concluded that the following pre-mining stress field gave the best representation for Deep Lead conditions (Sharrock and Duplancic, 2001):

$$
\left[\begin{array}{l}
\sigma_{1}, \sigma_{2}, \sigma_{3} \\
\delta_{1}, \delta_{2}, \delta_{3} \\
\theta_{1}, \theta_{2}, \theta_{3}
\end{array}\right]=\left[\begin{array}{ccc}
63.5 & 33.0 & 18.5 \\
2 & 18 & -71.8 \\
187 & 278 & 271.5
\end{array}\right]
$$

Where $\sigma=$ stress $(\mathrm{MPa}), \delta=$ plunge (Degree), and $\theta=$ trend (Degree). This stress field has since been used for subsequent stope stability analysis work and sequencing.

\section{INITIAL DEEP LEAD STOPE DESIGNS}

\subsection{Feasibility Study and Trial Stope}

The Deep Lead conceptual stope designs were based following a feasibility study which considered geotechnical interpretation of core, numerical modelling, empirical analysis, historical experience relating to the known extraction of the 14 Orebody group (where conditions were perceived to be similar to those in Deep Lead), and a trial stope (again, where conditions were believed to be similar to Deep Lead).

The trial stope, 14BE (16B to 16E Sublevels), was extracted in 1997. Stope 14BE was located immediately beneath the 15L-15B crown pillar that was the base of the over lying MICAF. At the time, the primary east-west orientated stress was believed to be representative of the stresses passing beneath the Lead Mine and through the 19L haulage. The $14 \mathrm{BE}$ stope had to a lesser degree, the southern abutment stress due to the extracted regions further to the south and west. $14 \mathrm{BE}$ was then extracted to failure via a north to south retreat to maximise the stress damage to the ground and to obtain an understanding of the abutment stresses.

Rock noise and spitting of wall rock began as soon as the slot was opened and were magnified immediately after the firing of production rings. Stress redistribution and associated rock noise continued for at least 12 hours following each production firing.

With the information coming from 14BE and results from rock mechanics investigations, Deep Lead stoping block and rib pillar dimensions were designed. As the stopes retreated back to the central $6755 \mathrm{x} / \mathrm{c}$ infrastructure pillar, the voids were reduced and the pillars increased in strike span to counter the perceived stress increases associated with a reducing stress window.

\subsection{Mine Life Extension for the Lead Mine}

In 1998, a decision was approved to extend the production life of the Lead Mine. An additional 4 years of mine life meant that the high grade Deep Lead region was the obvious choice to expand, especially as there were known reserves down to 21D Sublevel. Designing Deep Lead to accommodate the extended mine life proved to be a complicated issue, as the original mine design was based around a limited 3 year operational time frame. Designs had to take into consideration extracting the remaining portion of 14 Orebody that was underlying the region all ready being extracted and filled.

\subsection{Sequence 1}

The least favourable option (but the best for managing the stress) was to complete the $\mathrm{D}$ and E block extraction between $19 \mathrm{~A}$ and 20C (refer to Figure 8). The extraction of the B and $\mathrm{C}$ block was to be delayed until the development on $20 \mathrm{~A}$ and 21D was complete and then retreat the entire height of 14 Orebody from south to north as sub level open stopes with a potential primary-secondary sequence. The lost production 
from Deep Lead during the delay and the additional expense of a completely new decline that ramped down the north extent, deemed the option to fail.

\subsection{Sequence 2}

The next option was to complete the extraction of the $\mathrm{D}$ and E block. Then access, through the existing 20B 12 Orebody development (see Figure 7), the north extent of the 14 orebody and retreat the $\mathrm{B}$ and $\mathrm{C}$ and the remaining $\mathrm{D}$ and $\mathrm{E}$ regions from south to north. This meant delaying 12 Orebody extraction and tramming the underlying 14 Orebody through the $6755 \mathrm{x} / \mathrm{c}$ on 20B, which was structurally at risk due to the increasing stress. This also meant a hangingwall decline to access the 21D level, which would suffer when the hangingwall rock relaxed into the 14 Orebody voids. Again a production delay to the $\mathrm{B}$ and $\mathrm{C}$ block was part of the design and this option did not proceed.

\subsection{Sequence 3}

The eventual design saw the P69 decline extended down the footwall side of 14 orebody to ensure structural integrity to access 20A and 21D. The 14 Orebody on 20A was accessed again through the $6755 \mathrm{x} / \mathrm{c}$ and developed north and south to increase the sill drive development rate. On 20A, the sill drive was also developed from a northern access, which also provided for a complete south to north retreat of the stopes. On 21D, the P69 decline accessed the orebody only from the northern end in preparation of a complete south to north retreat of the remaining ore.

The southern geometry profile of 14 orebody aligned with a staggered inclined advance front, a profile the rock mechanics recommended to minimise stress-related damage. The advantage of this option was the most southern B block stopes could begin their extraction, as soon as development allowed to begin setting up the inclined advance front, while the lower 20A and 21D development proceeded.

\section{EARLY STOPE PERFORMANCE AND ISSUES}

Extraction from the north was on schedule due to the good competent rockmass characteristics and favourable stress conditions. However, the southern extraction was being continually delayed due to the degradation of the 20B/20C sill drive, and at times violent rock noise. The slow advance rate of the $20 \mathrm{~B} / 20 \mathrm{C}$ heading was the result of having to allow 12 hours for the rockmass to settle before personnel re-entered the heading after firing and the rehabilitation of the 20B/20C drive behind the existing face.

14E3 was the first Deep Lead stope extracted (in the northern extent of the region). The burdens, toes spacings and stand offs from the footwall and hangingwall were based on the 14BE trial stope (refer to Section 6.1). The hangingwall proved to be far more competent than that of 14BE.

The design had the cut-off slot at the southern access end of the span with main rings on the northern side. The firing then involved firing toes to obtain minimum void, then firing the collars of the slot and main rings. The intention was to throw the fragmented muck up against the draw point and increase conventional mucking quantities. When undercut, the collar region displayed no deterioration due to stress redistribution. No rock noise was heard during the extraction and the predicted span of $39 \mathrm{~m}$ suffered only underbreak (considered as a consequence of the initial understanding and learning of the Deep Lead conditions).

The 14E2 stope was designed to extract $40 \%$ of the $14 \mathrm{E} 3-$ $14 \mathrm{E} 2$ rib pillar since little ground deterioration was evident to maintain the full sized pillar. The competency of the brow during the extraction of 14E3 also meant the slot could be confidently located on the extent of the designed stope. The end result was a good recovery of the hangingwall ore and the footwall peeled back to the undercutting development footwall plane.

14D4 stope was designed as a north and a south portion due to the O68 fault splitting the stope with a $10 \mathrm{~m}$ horizontal displacement. The stope was produced without displaying signs of stress redistribution and the O68 fault did not effect the extraction of the ore. The $6905 \mathrm{x} / \mathrm{c}$ pillar suffered no noticeable damage or microseismicity during the extraction of the northern retreat stopes of D and E block.

14D3, 14D2, 14D1 were all extracted from early 2001 to mid 2002. As each stope was extracted in the sequence, the behaviour of the stopes improved. All brows stood up with no failure experienced. Some HW overbreak and FW underbreak occurred in 14D3, but offsets were trialed and in 14D1 an excellent result was achieved.

The 14CBLHUH scavenger stope was the first southern Deep Lead void to be created. The up hole retreat was located above 19L and had a strike width from $2.5 \mathrm{~m}$ to $5.5 \mathrm{~m}$ over a $25 \mathrm{~m}$ span with a shallow $47^{\circ}$ footwall plane (see Figure 13). The rock noise generated after the first shot was a clear indication of the stress redistribution and created concern as to whether the up-hole components above the 19L-20C stopes should be taken with the down hole stopes. The collapse of the remaining 19A-19B crown pillar after the up-hole retreat was extracted was highly likely. The collapse of the fill in the 14 Orebody stopes above 19B would expose the stope crowns up on $16 \mathrm{~B}$ and $16 \mathrm{E}$, which in turn would potentially de-stabilise the crown pillar between 16E and 15B.

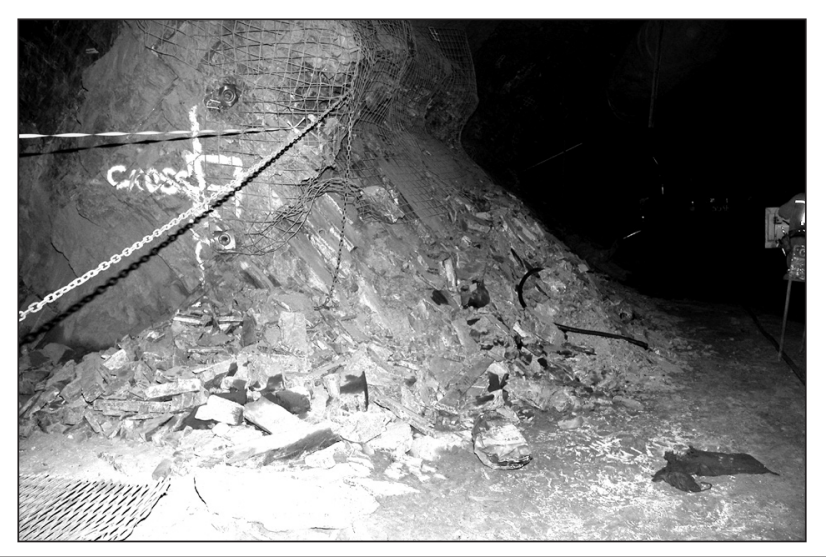

FIG. 13 Photograph looking south of 14CBLH, 19/19A Sublevel, showing the shallow dip of the orebody

\section{SEISMIC MONITORING IN DEEP LEAD}

\subsection{A Qualitative Approach}

Initially, microseismic activity was monitored by qualitative means in order to determine the level of activity during the development of Deep Lead. Underground operators were asked to complete a Rock Noise Report if any activity was heard and / or felt. The information included in such reports consists of the time and location of the noise, a description of what the sound was like, a description of what the sound felt like, and other conditions noticed (for example, rockmass damage, rockmass movement). From the information provided, it was possible to determine the relative size of the event. With such reports, it is very important to provide feedback to operators, particularly as it demonstrates the importance of their observations and encourages them to complete further reports.

As the number of completed reports increased, and subsequent investigations carried out, it became clear that the qualitative approach, while providing valuable information, 
was not adequate for the conditions developing in Deep Lead. It was apparent that a quantitative approach in monitoring microseismic activity was needed.

\subsection{A Quantitative Approach}

An ISS seismic monitoring system was installed in Deep Lead prior to the commencement of stoping. The system was designed around an extraction sequence for 14 orebody with the base extraction level on 20B/C Sublevel. The array installed consisted of six triaxial geophones (refer to Figure $8)$, with three in the footwall and three in the hangingwall. The array could be considered quite flat, however owing to the placement of development and the current mining focus, the array provided adequate coverage.

However, when Deep Lead was extended down to 21D Sublevel, the seismic network was not. As a result, the highest sensor in Enterprise Mine (located at 23D, some distance below Deep Lead) was the main sensor that provided the vertical extent for the Deep Lead network (other deeper sensors in Enterprise Mine would occasionally be triggered).

The most recent issues in Deep Lead have lead to a proposal to extend the seismic network to include an additional 4 geophones ( 1 triaxial and 3 uniaxial) located at the base of Deep Lead on 21D Sublevel. A sensitivity analysis of the new network (Cronje, 2004) demonstrated a clear improvement in location accuracy and network coverage, as depicted in Figure 14 (after Cronje, 2004).

Current

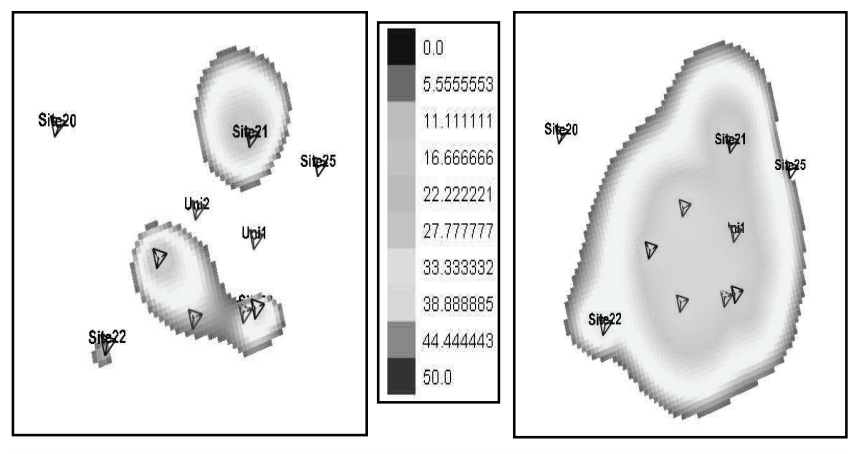

FIG. 14 Sensitivity analysis of the improved seismic coverage in Deep Lead with proposed additional geophones (shown by the unlabelled triangles), as seen from 20C Sublevel

\section{CURRENT STOPE PERFORMANCE AND ISSUES}

Extraction from Deep Lead has continued over the years, with issues being managed without much impact on the operation. One change that did evolve from Deep Lead as a result of experience was that of brow protection (significant brow failure was being experienced). This was achieved by shotcreting over existing bolts and mesh and installing cable bolts through the shotcrete prior to production starting. This practice has proved to be very successful, with very few brow failures occurring in subsequent stopes.

\subsection{Sequence 4}

In early 2003, Deep Lead extraction was behind schedule, which was then further compounded by a lack of available fill. As such, a change in extraction strategy was necessary, which resulted in a sequence based on larger mining blocks (strike length in excess of $100 \mathrm{~m}$ ) being designed.

Each of the larger blocks was to be extracted as a series of stopes and pillars that would only be filled after the entire block was complete. With standard Deep Lead spans at $20 \mathrm{~m}$, there were at least four voids in each sequence, which meant that the first void could potentially be left open for as long as a year before being filled.

Hangingwall performance was good for the first couple of stopes extracted under the 'large blocks' approach. The first issue appeared when the second void in the sequence was created, resulting in a pillar which began to deteriorate. As a result of the pillar failure, it was then decided to increase the size of the pillars. However, the pillars continued to fail. Many of the immediate access drives also suffered damage and generally required rehabilitation prior to being able to extract the next stope. The damage appeared to be stress related, with the seismic network only picking up the larger events (although rock noise was continually heard underground).

\subsection{Block C3 Caving Failure}

In early 2004, extraction began for 14C-C3-21D. C3 consisted of two spans of $15.5 \mathrm{~m}$ strike lengths separated by a $12 \mathrm{~m}$ strike length pillar. Each of the spans was to be extracted in two sections: a series of upholes from the mucking level (on 21D) followed by a section of downholes from the top level (20A). Due to production requirements, the two uphole sections were extracted first. The downhole section of the southern stope was then extracted and firing of a fill winze began.

The hangingwall of the northern section (full height) failed to a depth of $5 \mathrm{~m}$ until it reached the more stable 14 Orebody hangingwall. During the firing of the winze, the back of the full height stope section began to unravel (approximately $5 \mathrm{~m}$ above the original back) and the northern ( $1 / 2$ height) section began to experience some hangingwall and back failure.

Due to deteriorating ground conditions it was decided to start firing the last down-hole section. The first firing of the cut-off for the section induced significant stress damage in the 20A drive and more material unravelled around the partially fired fill winze. A rapid second firing of the cut-off brought about a significant failure of the sill drive's hangingwall. Ultimately $50 \mathrm{~m}$ of drive failed, heavily damaging an access cross-cut (see Figure 15). Significant levels of microseismicity were recorded by the seismic system (see Figure 16), in addition to rock noise being heard and felt underground (described as continuous popping and cracking, with intermittent thumps). The area was then sealed and filled, with the access cross-cut no longer accessible.

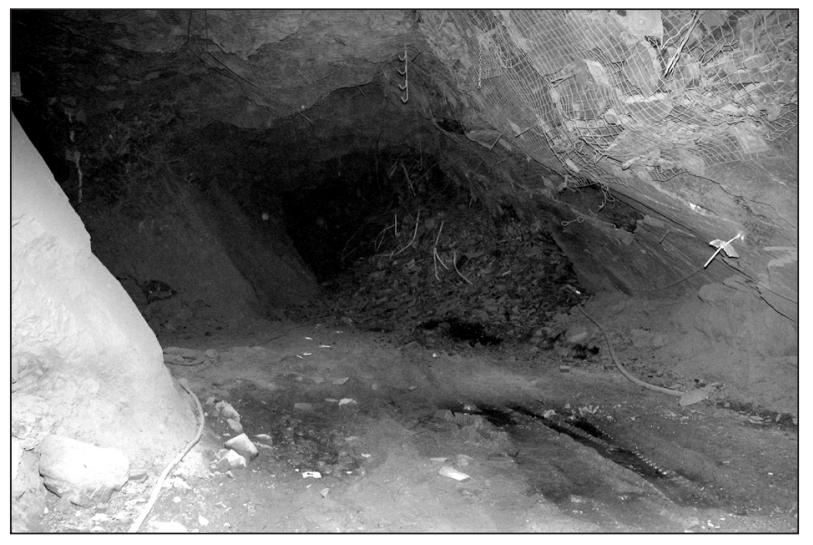

FIG. 15 Photograph looking south showing hangingwall deterioration along the sill drive on 20A Sublevel, associated with the $\mathrm{C} 3$ caving failure 


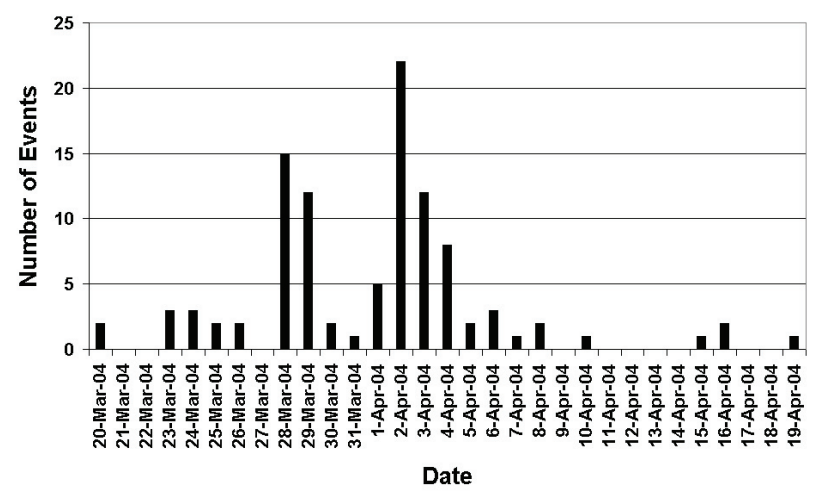

FIG. 16 A graph showing recorded events from the seismic system, which encompass the $\mathrm{C} 3$ failure. The peaks in the graph relate to activity within the stope and progressive failure in the sill drive on $20 \mathrm{~A}$ over several days

Due to the magnitude of the failure, it was necessary to review the mining sequence and approach to stoping.

\subsection{Current Sequence}

An analysis was carried out for the $\mathrm{C} 3$ failure which resulted in developing a new sequence that best managed the stress issues that had now become apparent (Beck, 2004b). Of major significance was the increasing need for accurate monitoring of seismic activity, primarily in the central pillar. As much of the failure was stress driven it became critical to know where stress was exceeding the capacity of the rockmass.

Relevant rehabilitation in the surrounding areas of the C3 failure will only take place when all the voids in the area have been tight filled (probe holes will be drilled to ascertain this). As a result of this failure, a new sequence was devised with a much lower extraction ratio.

Microseismic activity continues to be monitored in Deep Lead. Figure 17 shows the events recorded during the period March 2004 and July 2004 inclusive. This sample of events (showing the total number of events per week, but not associated with firing time) highlights the general trend of microseismic activity now seen in Deep Lead.

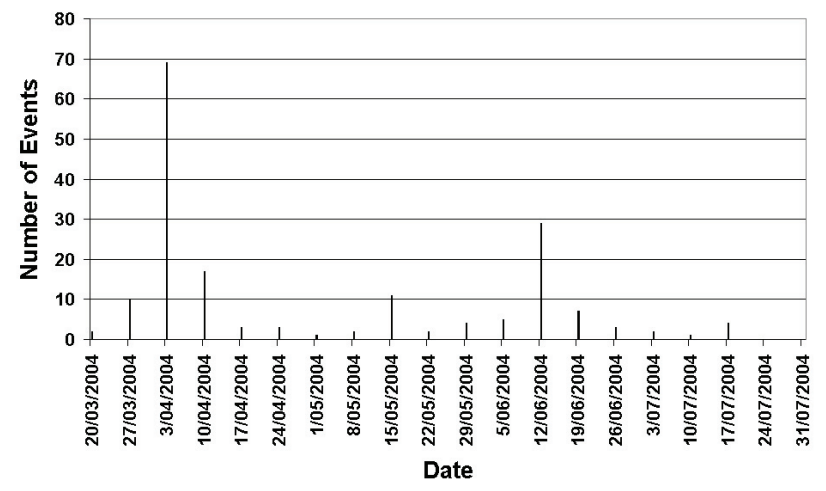

FIG. 17 A graph showing recorded mirco-sesimic activity from Deep Lead over a period of 4 months (April to July 2004)

Figure 17 shows the activity associated with the C3 failure in April 2004 (as seen in Figure 16), after which the activity drops down. This low-level trend continues through to mid June 2004, when an increase in activity was recorded which was associated with production from stope 14C-CPN-21D. The rock noise recorded related to rockmass deterioration or overbreak from within the stope itself. There was no damage to the surrounding development drives. Microseismic activity after this time is then again seen to reduce.

\section{LEARNING EXPERIENCES}

The operational life of the Lead Mine has been extended several times. With each of the extensions, so rescheduling of the stoping sequence has been undertaken, with decisions being made to extract more of the mining reserves than was previously planned.

The original 3-year Lead Mine life span (with production completed by 1999) certainly influenced the original design to extract only the top $35 \mathrm{~m}$ of Deep Lead. If today's time line for the Lead Mine was known back in 1996, then the design of the long-term recovery of Deep Lead would have likely promoted a south to north retreat to counter the cyclical stress redistribution. A northern access decline would have made an impact on production with increased hauling distances, but the stress damage should have been manageable.

Conceptual designs were created once the Lead Mine life was extended. These design options attempted to extract the maximum ore by sequences that attempted to counter detrimental stress redistributions. The lessons learnt between 1996 and 1999 were incorporated in these designs to establish an entire strike retreat from south to north.

A thorough analysis of the total stress field should have been addressed after the last expansion of Deep Lead down to 21D Sublevel. However, due to the location of the Deep Lead region in relation to the stress field transition zone, difficulties would have resulted (it is doubtful that a comprehensive understanding of stress would have been achieved).

The coverage provided by the installed seismic system should have been extended once development had been completed on 21D Sublevel and prior to stope extraction starting in this lower region.

As production in Deep Lead continues (particularly with stope extraction progressing towards the major cross-cut pillars), the proposed extension of the current seismic system will aid in reducing possible production losses due to microseismicity and improve the mine design process through the understanding of the mining and rockmass conditions conducive to the on-set of microseismic activity.

\section{CONCLUSION}

Much has been learnt from Deep Lead, with the area presenting many new challenges to personnel. Significant experience and exposure to high stress and associated rock noise conditions has been gained.

While it had been identified that Deep Lead was going to be a high stress area, and microseismicity was expected, no one expected the levels to be as high as they were.

Obviously, extending the life of the Lead Mine after the Deep Lead infrastructure had been established was not ideal. Designing infrastructure and extraction sequences for the entire Deep Lead region would have resulted in improved stress management. However, there remains the question of how well the stress environment in the transition zone is understood and how this could have been improved (even with the power of hindsight).

Currently, prior to production starting from each individual Deep Lead stope, a formal risk assessment is carried with all relevant technical and operational personnel taking part.

Taking into account the level of complexity that has been presented to the Lead Mine (both in terms of underground in situ conditions and changing mine physicals), it is felt that significant achievements have been made in terms of maintaining Deep Lead as a continuously producing source. 
Deep Lead conditions underground continue to be technically challenging. However, the experience and knowledge gained since mining started in 1996, have allowed the area to remain as an active producing source, as opposed to ceasing production (which has been the case for other mines with similar conditions).

\section{ACKNOWLEDGMENTS}

The authors wish to thank the management of the Mount Isa Mines, Xstrata Zinc for the support shown towards the paper and the permission to publish.

\section{REFERENCES}

Beck, D. (2004a) Extraction of 7, 8 and 12 Orebodies. External Report, Beck Mining Engineering (May).

Beck, D. (2004b) Recent problems in Deep Lead and the short term 14 O/B mining sequence. External Report, Beck Mining Engineering (April).

Cai, Y.J. (1996) NFOLD analysis for Deep Lead excavation. Internal Memorandum, Mount Isa Mines Limited (CAI/7.7/RES.MIN/D9.2).

Cronje, F. (2004) Mt Isa Mine: Sensitivity - micro seismic system. External Report (presentation), ISS Pacific Pty Ltd (May).

Lee, M.F. (1980) Review of MICAF rock mechanics. Internal Technical Report, Mount Isa Mines Limited, Mount Isa Operations, No. RES MIN 58.

MacLeod-Carey, I.R (1969) Rock mechanics problems associated with the extraction of highly inclined parallel orebodies. PhD Thesis, University of Newcastle-Upon-Tyne, United Kingdom.

Sharrock, G. and Duplancic, P. (2001) Stress in the Deep Lead reserve - an analysis of stress in Deep Lead. Internal Report, Mount Isa Mines Limited.

Sharrock, G., Slade, N., Thin, I. and Duplancic, P. (2002) The prediction of stress induced caving on a mining abutment. In Proceedings of First International Seminar on Deep and High Stress Mining, Perth 6-8 November 2002, Section 13, pp. 1-21.

Slade, N.M. (2002) Rock mechanics notes for the extraction of 14 Orebody - Deep Lead - B and C Blocks. Internal Memorandum, Mount Isa Mines Limited (NMS/7.7/MINRES/D9.2).

Tyler, D.B. (1996) Deep Lead conceptual stope designs. Internal Memorandum, Mount Isa Mines Limited (DBT/7.7/MIN RES/D9.6). 